\title{
Superficial Temperature Distribution Patterns Before and After Physical Activity in School Children are Indicative for Personalized Exercise Coaching and Disease Prevention
}

\section{Agnieszka Dębiec-Bąk}

Wroclaw university of Health and Sport Sciences

\section{Anna Skrzek}

Wroclaw University of Health and Sport Sciences

\section{Halina Podbielska}

Wroclaw University of Science and Technology: Politechnika Wroclawska

Olga Golubnitschaja ( $\nabla$ olga.golubnitschaja@ukbonn.de)

Friedrich-Wilhelms-Universität Bonn

\section{Małgorzata Stefańska}

Wroclaw University of Health and Sport Sciences

\section{Research Article}

Keywords: Predictive preventive personalized medicine (PPPM / 3PM), thermoregulation, thermography, age-dependent, body temperature, physical activity, patterns, body mass, height, fatigue, indicator, personalized coaching, multi-factorial, thermovision analysis, stratification, assessment tool, school children, 7-12 years old, fitness training, innovative approach, socio-economic disparity, healthcare policy

Posted Date: October 25th, 2021

DOl: https://doi.org/10.21203/rs.3.rs-994914/v1

License: (c) (i) This work is licensed under a Creative Commons Attribution 4.0 International License. Read Full License

Version of Record: A version of this preprint was published at EPMA Journal on November 5th, 2021. See the published version at https://doi.org/10.1007/s13167-021-00262-1. 


\section{Abstract}

\section{Background}

Thermoregulation is highly individual and predictive for potentially cascading pathologies. Altered and deficient thermoregulation is considered an important diagnostic indicator which can be of great clinical utility for specialised screening programmes and individualized prediction and prevention of severe pathologies triggered early in life.

\section{Working hypothesis}

Individual thermoregulation can be objectively assessed by thermo-vision camera before and after exercises in school children stratified by age and gender that may be of great clinical utility for personalized training early in life in the framework of 3P medicine.

\section{Study design}

In this study 60 female and male primary school children were exposed to physical exercises in the form of 45-minutes general fitness training. The subjects under examination were stratified by age: Group 1 (7year-olds), Group 2 (9-year-olds), and Group 3 (12-year-olds). Superficial body temperature patterns were measured by means of thermovision camera before and immediately after exercises, as well as 15minutes after the rest. Temperature patterns were analyzed in 12 areas of the body front and back, covering trunk, upper and lower limbs.

\section{Results}

The obtained results revealed an individual and age-depended difference in response of the body to exercises.

The first measurement prior to exercise (Measurement 1). revealed no statistically significant differences in the mean surface temperature of all analyzed areas between 7- and 9-year-old children. Further, 7 and 9-year-old children did not differ significantly in the mean temperature recorded in the trunk compared to the 12-year-old children. However, in 12-years-old children, statistically significant higher values of the mean temperature of the upper and lower limbs, were observed compared to the group of 7-year-olds and significantly higher values of the mean temperature of the lower limbs compared to the group of 9-yearolds.

Immediately after exercises (Measurement 2), a statistically significant decrease in the temperature was noted in all groups, in all areas of the body. The greatest temperature change was observed in 12-yearolds, while the least one was measured in the youngest subjects. The statistically significant relation between the average trunk temperature of 7-year-old and 12-year-old children, was observed: lower values of the mean temperature of the front and back of the trunk were noted in the group of 12-year-old children 
compared to the group of 7-year-olds. A significantly lower average temperature of the back of the trunk compared to the youngest group was also recorded in 9-years-old children.

The study_performed after the 15-minutes recovery time (Measurement 3). showed an increase in the average temperature of all analyzed areas. In all subjects, the mean temperature recorded in Measurement 3 did not differ significantly from the initial ones (Measurement 1, prior to exercises). Only the mean temperature of the trunk back of 12-year-old children was significantly lower after the rest period compared to the initial examination. In all groups the temperatures after exercises followed by a 15 minutes recovery, returned to the initial ones, except of the trunk backs of 12-year-old children, where the temperature was lower than before exercises.

\section{Conclusions and expert recommendations in the framework of 3PM}

Thermovision analysis is an effective tool to assess individual thermoregulation and to stratify school children for personalized exercise coaching. Body exercise-based disease prevention early in life is effective when tailored to the person: multi-parametric guidance for prescribing exercises individually is needed. Contextually, proposed individualized training approach should be adapted to the age-dependent particularities and individual thermoregulation.

\section{Introduction}

\section{Physical activity is highly effective for disease prevention}

The physical activity is in focus of many national and global recommendations, pointing out its great potential of diseases prevention $\left[{ }^{1}, 2,3,4\right]$. Regular participation in physical exercises of children and youth have many health benefits, as e.g. enhancing muscular strength, promoting bones healthiness, positively influencing cardio-respiratory system $\left[{ }^{5}, 6\right]$. Positive impacts towards mental health are also observed [ $\left.{ }^{7}\right]$. Physical activity in children should be specially promoted as it is a good prevention tool of adolescent obesity $[8,9,10]$.

However, the optimal doses of health-enhancing physical activity of an individual are difficult to determine. During physical activity numerous changes in the human body are observed. Activation of the sympathetic nervous system speeds up the transport of blood and, consequently, oxygen. Temperature increase is one of the signals sent to the brain informing about the body fatigue $\left[{ }^{11}\right]$.

\section{Thermoregulation is indicative for health status and adaptive mechanisms' functionality}

Thermoregulation processes determine the heat balance and ensures thermal homeostasis of the living organisms. This ability develops along with other systems in the process of human ontogenesis. Maintaining thermoregulatory processes at the appropriate level depends on the degree of thermoregulatory efficiency of each person and capacity of the circulatory and respiratory systems. The production of heat in the body influences numerous metabolic processes in cells and muscle activity. 
Metabolism, regulated by hormones (e.g. thyroxine, testosterone, adrenaline, noradrenaline), also affects the temperature changes. A healthy human maintains almost constant inner organs temperature. The changes are small and oscillate around $0.6^{\circ} \mathrm{C}$. The situation is different for superficial skin temperature.

This parameter reflects numerous factors, as inner temperature, efficacy of skin microcirculation, but also depends on the ambient temperature and physical activity. When performing strenuous exercises, human skin may reach the temperature even up to $38.3^{\circ} \mathrm{C} \otimes 40^{\circ} \mathrm{C}$. When the body is subjected to cold, it reduces the skin temperature to $35.5^{\circ} \mathrm{C}$ or even lower. The ability to maintain a constant inner body temperature is determined by the metabolic and thermoregulatory efficiency $\left[{ }^{12},{ }^{13}\right]$.

The hypothalamus is responsible for integrating incoming information from thermos-detectors located in the skin, in the spinal cord, in other parts of the brain, and from receptors in the hypothalamus itself $\left[{ }^{14}.\right] T h e$ stability of maintaining body temperature depends on the balance between the processes of heat generation and dispersion. Thermal balance is a dynamic process that requires the continuous adjustment of individual thermoregulatory mechanisms to environmental conditions $\left.{ }^{15}\right]$.

\section{Body temperature patterns are instrumental for individualized physical activity}

There are some reports on the relationship between physical performance and the tolerance of body temperature increase. McLellan's $\left[{ }^{16}\right]$ research indicates that regular physical exercises have a positive effect on the efficiency of the circulatory system, which translates into the possibility of a greater increase in internal temperature until the body feels tired. Drust et al. $\left.{ }^{[17}\right]$ revealed that body fatigue does not occur as a result of the accumulation of exercise metabolites, but as a result of a significant increase of internal temperature, which has an adverse effect on brain work. Improving the ability to efficiently remove heat from the body is important e.g. to athletes as it allows them to continue strenuous exercises [ $\left.{ }^{18}\right]$.

In children, as the entire body still develops, the thermoregulatory abilities change progressively. Biological maturation of each system occurs individually. Thermal control in children is not yet fully developed, which means that their resistance to thermal stress is much weaker compared to adults $\left[{ }^{19}\right]$.

\section{Thermoregulation and individualized physical activity early in life: Application of 3PM concepts}

Children and the elderly react differently to changes in ambient temperature. Their thermoregulatory processes cope with excessive increase or decrease of ambient temperature in a less effective way. Noteworthy, newborns have undeveloped resistance against cold provocation and therefore demonstrate deficient thermoregulation $\left.{ }^{20}\right]$. Therefore, analyzing age-stratified thermoregulation in children in response to individualized physical activity is a very important issue. Children employ different thermoregulatory strategies than adults $\left[{ }^{21}\right]$. Regarding heat-dissipation, child body engages more dry heat exchange, while in adults it is evaporative heat loss, thus children have limited ability to lose heat through evaporation. Promoting physical activity early in life is crucial for maintaining physically and mentally vibrant throughout the life. Therefore, research activities dedicated to functioning children's thermoregulatory processes in response to physical effort are of great importance. To this end, 
thermographic approach is instrumental in the area. The analysis of surface body temperature through thermography provides useful information on the efficiency of thermoregulatory processes [22]. Infrared thermography, as a non-invasive non-contact method, found some applications in contemporary medicine. It can be used for detection of different diseases like i.e. tumors [ $\left.{ }^{23}\right]$. Thermal temperature mapping has also been applied for skin lesion differentiation $[24,25,26]$. The distribution of superficial temperature is a significant parameter in the assessment of various medical physiotherapeutic procedures, as well as in sports medicine $[27,28,29,30]$.

\section{Working hypothesis}

Individual thermoregulation can be objectively assessed by thermo-vision camera before and after exercises in school children stratified by age and gender that may be of great clinical utility for personalized training early in life in the framework of 3P medicine.

\section{Study design}

\section{Study participants}

The research group consisted of 60 pupils of both sexes of primary school. The subjects were divided into three age groups, each of 20 persons. Group 1 consisted of first-grade students at the age of 7 years, with an average body weight of $25 \mathrm{~kg}( \pm 3.7)$ and a height of $124.2 \mathrm{~cm}( \pm 5.2)$; Group 2 included thirdgrade students at the age of 9 years, with an average body weight of $34.5 \mathrm{~kg}( \pm 5)$ and a height of 141.6 $\mathrm{cm}( \pm 6.5)$; Group 3 comprised sixth-grade students, 12 years, with an average body weight of $40.3 \mathrm{~kg}$ ( \pm $5.5)$ and a height of $148.4 \mathrm{~cm}( \pm 6.4)$. The inclusion criteria were age matching one of these three groups, good general health of the child, no injuries that would prevent from training and consent of a parent or legal guardian. The exclusion criteria included poor general health of the pupil and doctor's recommendation excluding the child from the active participation in physical education classes. The group characteristics are depicted in Table 1.

Table 1. Body mass and height in the examined groups. 


\begin{tabular}{|c|c|c|}
\hline \multicolumn{3}{|c|}{ Groups characteristics; body mass and height } \\
\hline Group 1 & Group 2 & Group 3 \\
\hline $25 \mathrm{~kg}( \pm 3.6)$ & $34.5 \mathrm{~kg}( \pm 5)$ & $40.3 \mathrm{~kg}( \pm 5.5)$ \\
\hline $124.2 \mathrm{~cm}( \pm 5.2)$ & $141.6 \mathrm{~cm}( \pm 6.5)$ & $148.4 \mathrm{~cm}( \pm 6.4)$ \\
\hline \multicolumn{3}{|c|}{ Girls characteristics; body mass and height } \\
\hline Group 1 & Group 2 & Group 3 \\
\hline $24.6 \mathrm{~kg}( \pm 3.9)$ & $34.1 \mathrm{~kg}( \pm 4.8)$ & $39.0 \mathrm{~kg}( \pm 5.2)$ \\
\hline $122.8 \mathrm{~cm}( \pm 5.0)$ & $140.8 \mathrm{~cm}( \pm 7)$ & $150.4 \mathrm{~cm}( \pm 5.0)$ \\
\hline \multicolumn{3}{|c|}{ Boys characteristics; body mass and height } \\
\hline Group 1 & Group 2 & Group 3 \\
\hline $25.4 \mathrm{~kg}( \pm 3.4)$ & $34.9 \mathrm{~kg}( \pm 5)$ & $41.6 \mathrm{~kg}( \pm 5.3)$ \\
\hline $125.6 \mathrm{~cm}( \pm 4.8)$ & $142.5 \mathrm{~cm}( \pm 5.7)$ & $146.4 \mathrm{~cm}( \pm 6.9)$. \\
\hline
\end{tabular}

\section{Methods}

The general physical exercises for primarily school kids are organized routinely 3 times per week and lessons' duration is 45 minutes. The research project included three thermographic measurements of the superficial body temperature of the front and back of the body related to one 45 minutes long lesson. The thermal images were recorded in identical research conditions, in a research room with an ambient temperature of $21-22^{\circ} \mathrm{C}$ and relative humidity of $34-35 \%$. During the thermal recording in research room only one child and one researcher with thermal camera, were present. The research protocol was the same for each group.

Measurement 1 was performed before general physical exercises, Measurement 2 was taken immediately after the exercises, while Measurement 3 after 15 minutes of recovery time period. For each

Measurement, the thermal images were captured by means of ThermoVision FLIR SYSTEM T335 infrared camera (320 x 240 pixel resolution, a $50 \mathrm{mK} \mathrm{NETD} / 0.05^{\circ} \mathrm{C}$ thermal sensitivity and an extended temperature measurement range of $-20^{\circ} \mathrm{C}$ to $650^{\circ} \mathrm{C}$ ).

The average temperature was analyzed in the front and back of trunk, upper and lower limbs, according to the schema presented in Figure 1. The ThermaCAM Researcher Pro 2.10 software developed by FLIR Systems $A B$, was exploited for image analysis. The average temperature changes in the following 12 body regions, were determined: trunk area: front part (A1, $A 2)$, back part (A7, $A 8)$, upper limbs $(A 3, A 4, A 9$, A10), lower limbs (A5, A6, A11, A12) (Figure 1).

The training unit performed by the subjects was a modification of the seven fundamental movement patterns of the FMS (The Functional Movement Screen) [ $\left.{ }^{31},{ }^{32}\right]$. The exercises were preceded by a warm- 
up consisting of marching on the spot, trotting and exercises activating the shoulder and hip joints in all planes of mobility. The duration of the initial part of the exercise was 10 minutes. Next, the main part of the training with progressive effort was used, which consisted of a modification of the seven fundamental movement patterns tests of the FMS. Its duration was 30 minutes. Each movement pattern was repeated ten times. The following elements were included:

- shoulder girdle exercises in all planes and with a load (0.5-1 kg) above the head (overhead squats): they improve central stability, stability of shoulder joints and upper limbs strength,

- dumbbell overhead squats, squat jumps, squats with a cane in front or on the shoulders: they activate the gluteal muscles, biceps, quadriceps femoris, muscles of the trunk,

- single leg squats: they develop leg strength and have a strong stabilizing effect on the ankle and knee,

- split squats: they increase flexibility, balance and strength of the leg,

- stabilization exercises on a stable and unstable ground (Bobath balls and mats):

- supported kneel with uplifts of opposing limbs, e.g. upper right limb - bottom left limb;

- front holds on the forearms, i.e. the so-called forearm plank;

- front and back holds with the rise of one of the lower limbs;

- side plank with the rise of one of the lower limbs.

The following equipment was used to carry out the training unit: TheraBand tape with low resistance level, exercise canes, medicine and gym balls, balance soft disks, dumbbells, and exercise benches.

The part of the training unit in the form of recovery time after physical activity consisted of a slow march, reducing the movement amplitude until stop, and breathing exercises in a standing position. Its duration was 5-7 minutes.

The temperature changes determined from thermographic images were analyzed by statistical methods using Statistica software version 13.I from StatSoft with a license for the University of Physical Education in Wrocław. The Shapiro-Wilk test was used to check the normality of the distribution of the analyzed parameters. Statistical variables were described using the arithmetic mean and standard deviation. The assessment of differences between the analyzed variables for girls and boys was based on the results of multivariate analysis of variance. In the case of obtaining statistically significant mean differences between the compared groups, Scheffe's post-hoc test, was used. The significance of the mean differences between the results obtained for boys and girls was checked by the Student's $t$-test for independent samples. In all used statistical analyses, test and coefficients values at the level of $p<0.05$, were considered statistically significant. 
The research was approved by the Senate Committee of Ethics of Scientific Research at the University School of Physical Education (Permission 28.06.2007). The research participants and their parents or guardians were informed about the purpose and course of the study. Informed and voluntary consent was obtained for conducting the thermos-vision recordings.

\section{Results}

For each person, for each body area, the temperature distribution was recorded three times, as it was described above. Figures 2-5 represent exemplary recorded thermal images of analyzed body areas before general physical exercises (Measurement 1), immediately after the exercises (Measurement 2) and then, after 15 minutes of recovery time (Measurement 3).

The performed Student's $t$-test for repeated measurements for both sexes did not show differences at the level of statistical significance (Table 2). Therefore, in further analyses only age differentiations were considered.

Table 2. Age depended temperature differences in boys and girls, results of Student's $t$-test 


\begin{tabular}{|c|c|c|c|}
\hline \multirow{2}{*}{$\begin{array}{l}\text { Body part } \\
\text { p-value }\end{array}$} & \multicolumn{3}{|c|}{ Differences between girls and boys } \\
\hline & Group 1 & Group 2 & Group 3 \\
\hline \multicolumn{4}{|c|}{ Measurement 1 - before exercises } \\
\hline Trunk-front & 0,6830 & 0,6444 & 0,6762 \\
\hline Trunk-back & 0,5351 & 0,1656 & 0,8885 \\
\hline Upper limbs & 0,8689 & 0,5474 & 0,2452 \\
\hline Lower limbs & 0,4974 & 0,1055 & 0,1021 \\
\hline \multicolumn{4}{|c|}{ Measurement 2 - after exercises } \\
\hline Trunk-front & 0,2281 & 0,5516 & 0,4914 \\
\hline Trunk-back & 0,1128 & $0,0223^{*}$ & 0,8776 \\
\hline Upper limbs & 0,2750 & 0,0996 & 0,5595 \\
\hline Lower limbs & 0,1007 & 0,0963 & 0,2506 \\
\hline \multicolumn{4}{|c|}{ Measurement 3 - after recovery time } \\
\hline Trunk-front & 0,2489 & 1,0000 & $0,0423^{*}$ \\
\hline Trunk-back & 0,4403 & 0,1419 & 0,6870 \\
\hline Upper limbs & $0,0198^{*}$ & 0,7354 & 0,5337 \\
\hline Lower limbs & 0,3543 & 0,4301 & 0,8031 \\
\hline * statistically & I & le $(p<0$ & \\
\hline
\end{tabular}

In the next step, the average temperatures and standard deviations were calculated for examined body areas for Measurements: 1, 2 and 3 (Figures 6-9).

\section{Mean surface temperature prior to exercises}

Measurements carried out before the exercises (Table 3., Measurement 1) showed no significant differences in the mean surface temperature of all analyzed areas between 7-and 9-year-old children. Further, 7- and 9-year-old children did not differ significantly in the mean temperature recorded in the trunk compared to the 12-year-old ones. On the other hand, in 12-years-old children, statistically significant higher values of the mean temperature of the upper and lower limbs were observed compared to the group of 7-year-olds and significantly higher values of the mean temperature of the lower limbs compared to the group of 9-year-olds. 
Immediately after exercise (Table 3, Measurement 2), a temperature decrease in all groups, was observed (Figures 6-9). Significantly lower values of the mean temperature of the front and back of the trunk were recorded in the group of 12-year-old children compared to the group of 7-year-olds. A significantly lower average temperature of the back of the trunk compared to the youngest group was also recorded in 9year-old children.

\section{Mean surface temperature after fifteen minutes of recovery}

The study performed after the 15-minutes recovery time (Measurement 3) showed an increase in the average temperature of all analyzed areas (Figures 6-9). In all subjects, the mean temperature recorded in Measurement 3 did not differ significantly from the initial temperature (Table 3, Measurement 2). Only the mean temperature of the trunk back of 12-year-old children was significantly lower after rest compared to the initial examination (Figures 8 and 9, Table 3).

Table 3. Significance of differences in surface temperature values between the groups of comparison (Measurements: 1, 2 and 3). 


\begin{tabular}{|llll|}
\hline & Group 1 & Group 1 & Group 2 \\
& vs & vs & vs \\
& Group 2 & Group 3 & Group 3 \\
\hline Measurement 1 - before exercises & \\
\hline Trunk-front & 0.7450 & 0.5100 & 0.1627 \\
\hline Trunk-back & 0.1285 & 0.9377 & 0.2426 \\
\hline Upper limbs & 0.6062 & $\mathbf{0 . 0 0 4 1 *}$ & 0.0544 \\
\hline Lower limbs & 0.9890 & $\mathbf{0 . 0 3 1 2 *}$ & $\mathbf{0 . 0 4 4 2 *}$ \\
\hline Measurement 2 - after exercises & \\
\hline Trunk-front & 0.1689 & $\mathbf{0 . 0 2 9 5 *}$ & 0.7140 \\
\hline Trunk-back & $\mathbf{0 . 0 2 8 1 *}$ & $\mathbf{0 . 0 0 7 8 *}$ & 0.8856 \\
\hline Upper limbs & 0.4969 & 0.7806 & 0.8894 \\
\hline Lower limbs & 0.9999 & 0.9644 & 0.9674 \\
\hline Measurement 3 - after recovery time & \\
\hline Trunk-front & 0.6869 & 0.2349 & 0.6959 \\
\hline Trunk-back & 0.1249 & $\mathbf{0 . 0 0 6 0 *}$ & 0.4513 \\
\hline Upper limbs & 0.6308 & 0.4981 & 0.9752 \\
\hline Lower limbs & 0.8177 & 0.9764 & 0.9168 \\
\hline * statistically significant value (p<0.05) \\
\hline
\end{tabular}

The obtained results revealed an individual and age-depended difference in response of the body to exercises. Immediately after physical exertion (Measurement 2), the surface temperature of the whole body decreased in all subjects. The largest drop was recorded in the group of 12-year-olds. The changes ranged from $1.3^{\circ} \mathrm{C}$ to $2.4^{\circ} \mathrm{C}$. Comparing to Measurement 1 , smaller differences were noted in 7-year-olds (from $0.7^{\circ} \mathrm{C}$ to $1.2^{\circ} \mathrm{C}$ ).

Scheffe's post-hoc test was conducted to perform a detailed analysis of the differentiation of the results. The regression of the examined parameters in the trunk area showed statistically significant differentiation in each age group. A statistically significant difference between Measurements 1 and 2 was observed in each age group for the average trunk temperature and lower limbs and upper limbs in the group of children aged 9 and 12 (Table 4). 
Table 4. The significance of differences in surface temperature values obtained in each age group between the subsequent measurements (Measurements: 1, 2 and 3).

\begin{tabular}{|llll|}
\hline \multicolumn{5}{|c|}{ Group 1 } & Group 2 & Group 3 \\
\hline \multicolumn{1}{|c|}{ Trunk-front } \\
\hline 1vs2 & $\mathbf{0 . 0 2 7 6 *}$ & $\mathbf{0 . 0 0 0 0 *}$ & $\mathbf{0 . 0 0 0 0 *}$ \\
\hline 1vs3 & 0.9576 & 0.9932 & 0.2415 \\
\hline Trunk-back & & \\
\hline 1vs2 & $\mathbf{0 . 0 0 0 6 *}$ & $\mathbf{0 . 0 0 0 0 *}$ & $\mathbf{0 . 0 0 0 0 *}$ \\
\hline 1vs3 & 0.9999 & 1.0000 & $\mathbf{0 . 0 0 4 9}$ \\
\hline Upper limbs & & \\
\hline 1vs2 & 0.1518 & $\mathbf{0 . 0 0 0 1 *}$ & $\mathbf{0 . 0 0 0 0}$ \\
\hline 1vs3 & 1.0000 & 1.0000 & 0.9316 \\
\hline Lower limbs & & \\
\hline 1vs2 & $\mathbf{0 . 0 0 8 2 *}$ & $\mathbf{0 . 0 0 4 3 *}$ & $\mathbf{0 . 0 0 0 0 *}$ \\
\hline 1vs3 & 0.7018 & 0.3152 & 0.9584 \\
\hline * statistically significant value $(\mathrm{p}<0.05)$ \\
\hline 1, 2, 3 - Measurements: 1, 2 and 3 \\
\hline
\end{tabular}

\section{Data Interpretation And Discussion}

\section{Thermoregulation mechanisms in children are under development}

Compared to adults, thermoregulation mechanisms in children are under development $\left[{ }^{33}\right]$, so the resistance to thermal stress associated with physical activity could be lower than in adults. The efficiency of thermoregulation depends on the proper functioning of other systems, e.g. the respiratory, circulatory, endocrinal. It should also be noted that the ability to adapt to strenuous exercise is lower in children compared to adults, which is why the energy cost of physical work performed by the child is higher.

\section{Thermography as an important diagnostic tool}

The use of thermography as a diagnostic tool for the analysis of thermal patterns in the superficial body layers after physical activity enables to asses indirectly the thermoregulatory mechanisms and its differences between children of 7,9 and 12 years of age. Certain tendencies in the temperature distribution patterns could be observed in thermal images. The highest values were observed around the shoulder belt and in the trunk, whereas the lower extremities showed the lowest temperature. Such 
thermal distribution was also observed in other studies, e.g. by Dębiec-Bąk et al. in football players [ $\left.{ }^{34}\right]$. The reason for that is the vasculature system and the presence of inner organs. Our research showed a reduction in average temperature values in all subjects, immediately after physical exercises. The highest drop could be observed in the group of 12-year-olds. It may indicate the highest level of development of the body cooling processes in the group of the oldest subjects. Effective sweating mechanisms facilitate the removal of excess heat from the body during exercise. Inbar et al. $\left.{ }^{35}\right]$ compared thermoregulatory processes due to physical effort in three age groups: boys, young men and older men. The analysis of the results showed that the highest level of sweat secretion, which consequently cools down the body during exercise, is observed in young men. The oldest subjects were characterized by low efficiency of the sweating process, whereas the youngest boys had the lowest sweating levels.

\section{Particularities of thermoregulation in children}

The thermoregulation center gains the full independence between the age of 1 and 2 years. This capacity is lost again around the sixth decade of life, which results in similar, somehow impaired, thermoregulatory effectiveness of children and the elderly. Inoue et al. $\left.{ }^{[36}\right]$ in their research investigated how the ability to lose excess heat changes depending on age. Their results exhibited that children have low capacity to sweat in comparison with adults. Elimination of excess heat occurs by vasodilation of the skin vasculature. However, a high surface area to weight ratio can expose a child to excessive heat absorption in a hot climate. They also observed that due to the processes of involution, thermoregulatory abilities are again reduced in the elderly. Leites et al. [ $\left.{ }^{37}\right]$ conducted an analysis of thermoregulatory processes in men and 10-year-old boys taking into account the body mass in both groups. The subjects performed 80 minutes of physical exercises in the form of cycling in four twenty-minutes units. The lower production of sweat and heat energy per unit of body surface area in boys, were observed. In addition, it was noted that men produced more mechanical energy of muscle work compared to younger subjects. Similar results were obtained by Shibasaki et al. $\left.{ }^{38}\right]$, who compared the thermoregulatory response of the body in boys (10-11 years of age) and young men (21-25 years) performing moderate-intensity exercise. The differences between the groups concerned the amount of sweat secretion, which were higher in older subjects. These observations mentioned above and confirmed in our study, indicate the existence of a relationship between the degree of body cooling after exercises and age.

\section{Thermoregulation is efficient adapting human body to physical exercises}

An efficient thermoregulation mechanism enables the adaptation of the human body to physical exercises $\left.{ }^{39}\right]$. It is also vital to avoid the negative impact of heat on health and productivity, e.g. during physical work [ $\left.{ }^{40}\right]$. Cholewka et al. $\left[{ }^{41}\right]$ examined by means of thermography the correlation between recorded thermal parameters during endurance effort and the generated power. Strong correlation between these parameters was recorded. This proves the usefulness of thermography as a method for analyzing energy expenditure and also for designing the tests performed during the training cycle. 
In the research presented by Duffield et al. $\left[{ }^{42}\right]$, it was shown that people undertaking regular physical activity have better efficiency of maintaining thermal balance. Their defense mechanisms operate more efficiently than in non-training people. Regular physical activity affects thermoregulatory processes. This research and our examination may be a hint for parents, demonstrating that a systematic and wellchosen form of training can have a positive impact on the development of their child's thermoregulatory processes.

\section{Interpretation of temperature patterns after exercise and recovery time}

In our research, after the recovery time (Measurement 3), temperature values in children aged 7 and 9 were close to initial ones. However, the group of 12-year-olds was the only one which, after recovery time, did not reach the parameters recorded before exercises. This may be due to the fact that the oldest subjects showed the largest decreases in body temperature after general fitness training. The increase of the body surface temperature after the recovery time has also been demonstrated in studies by Chudecka and Lubkowska [43] using thermal recording. Having analyzed the temperature values in a group of volleyball players after a 90-minutes workout and a 10-minutes recovery time, they observed a drop of temperature immediately after physical exercise, while an increase in surface body temperatures followed the recovery time. These researchers conducted an analogous research in a group of handball players. The analysis of surface body temperature after a 10-minutes recovery time showed an increase in the temperature of the examined areas in all participants. In another study, Chudecka and Lubkowska [ $\left.{ }^{44}\right]$ noted that a return to the initial temperature after a recovery time is more effective in people with a higher value of maximum oxygen uptake. The human body during physical activity has a higher body temperature, due to the increased metabolism of the individual systems. In physiological response to such stimulus as training, cooling mechanisms protecting against hyperthermia are activated, mainly due to increased sweating and vasodilation. Efficient thermoregulation processes are also responsible for returning to pre-exercise temperature. The ability to maintain the thermal balance during daily physical activities and exercises is crucial for the proper functioning of the body [ $\left.{ }^{45}\right]$. The performed in our group analysis revealed that after physical exercises, a statistically significant decrease in temperature was noted in all age groups, in all areas of the body. The largest temperature reduction was observed in 12year-olds, while the smallest temperature drop was recorded in the youngest subjects (7-year-olds). After a given recovery time, the temperature did not return to the initial values only in the group of 12-year-olds. The observed significant differences in the body surface temperature between the group of 7-year-olds and 12-year-olds indicate the need to differentiate the level of exercise intensity depending on the age.

When planning training load and physical activity in school curricula, one should take into account individual reactions of thermoregulatory mechanisms in children, as well as the criterion of children's age. Trainers and teachers of sports activities in schools should be acquainted of the thermoregulatory efficiency of the child's body what may constitute the basis for prevention against injuries and strain of the locomotory system in school children.

\section{Concluding remarks and expert recommendations in the framework of 3P medicine}




\section{Thermoregulation is highly individual and predictive for potentially cascading pathologies.}

Well-controlled thermoregulation is crucial for physical and mental human health. A relatively narrow body temperature range of $36.5-37^{\circ} \mathrm{C}$ is rigorously kept allowing for timely enzymatic reactions by the optimal kinetic window and, therefore, an effective performance of all physiological processes. To this end, feeling cold is a normal response towards changing external temperatures, in order to win back the thermal comfort by physical activity and energy supply based on well-concerted regulation mechanisms. At low temperatures, an adaptive vasoconstriction and an increase in blood pressure and heart rates synergistically result in heat production and conservation for maintaining the optimal body temperature $\left[{ }^{46}\right]$. Maintaining thermal comfort is energetically costly $\left[{ }^{47}\right]$ and demands well-organised mitochondrial functionality. Mitochondriopaties causing dysfunction of the mitochondrial respiratory chain are characteristic for several pathologic conditions such as cancerous Warburg transformation and neurodegenerative disabilities, among others $[48,49,50]$.

For example, abnormal thermoregulation has been demonstrated for breast cancer patients, who are frequently deficient in achieving thermal comfort $\left.{ }^{[51}\right]$. They feel excessively hot or cold, when disease-free attenders are well comfortable with ambient temperature conditions [46]. To this end, pro-inflammatory cytokines (IL-1, IL-6, TNF-a) regulating the immune reactions $\left[{ }^{52}\right]$ are frequently overexpressed by cancer patients [ ${ }^{53}$ ] affecting thermoregulation by activating the cyclooxygenase 2 and production of prostaglandins $\left[{ }^{54}\right]$.

Another example: detectable brain temperature disturbances and brain-systemic temperature decoupling are involved in the stroke pathology $\left.{ }^{55}\right]$. Consequently, an altered brain thermoregulation may serve as a neuroimaging biomarker in CNS injury.

In conclusion, altered and deficient thermoregulation is considered an important diagnostic indicator which can be of great clinical utility for specialised screening programmes and individualised prediction of pathologies (individualised patient profiling) [ $\left.{ }^{56}\right]$. Contextually, altered thermoregulation patterns are instrumental for specific phenotypes useful for detection of sub-optimal health conditions that can be exemplified by the Flammer syndrome phenotype and associated cascading pathologies $[51,57,58]$.

\section{Body exercise-based disease prevention is effective when adapted individually: multi-parametric guidance for prescribing exercises is needed}

As stated above, physiologic versus abnormal thermoregulation is functionally linked with regular physical activities and optimal energy supply. These individual components are well-concerted together via systemic effects being therefore highly indicative for individual healthcare status and prediction of associated pathologies. In this context, individually adapted physical activities are crucial for the targeted disease prevention as stated in both EPMA Position Paper $\left.2021{ }^{[59}\right]$ and ajoint position paper of the Suboptimal Health Study Consortium and European Association for Predictive, Preventive and Personalised Medicine. EPMA J. 2021 [ $\left.{ }^{60}\right]$. To this end, topic dedicated research groups emphasise an importance of diversified physical activities in early childhood. Thus, most recently performed studies 
indicate that diversified physical activity at age six is important for developing optimal physical activities in general and, in particular, motor competence in adolescence. The authors do stress the point that not only the amount and intensity but specifically an increased diversity of children's daily physical activities is decisive for optimal behavioural patterns and health promotion later on in life $\left[{ }^{61}\right]$.

Noteworthy, socioeconomic status was demonstrated to be inversely associated with outcomes related to the intensity and quality of youth physical and sports activity. To this end, a cross-sectional survey with 1038 students in 5-12th grades in USA (King County and Washington including 50\% girls, 58\% non-White, and $32 \%$ from homes where languages other than English are spoken) was conducted. Responders described their physical activity and sports experiences and demographic factors such as family affluence categorized as low, medium, and high [ $\left.{ }^{62}\right]$. For children from low-affluence families, lower intensity of physical activity and rates of ever playing sports were reported. The barriers to sports these children described as "don't feel welcome on teams" and "too expensive", among others. The disparity results in three times higher odds of meeting physical activity recommendations as well as three times higher odds of ever participating in sports reported for middle school children from high-affluence families compared to peers from low-affluence families. Consequently, socio-economical particularities have to be taken into consideration for coaching individually adapted physical activities to reach satisfactory health promoting benefits.

American College of Sports Medicine position stand stated that although general recommendations for physical exercises have been elaborated, the exercise program should be modified according to an individual's habitual physical activity, physical function, health status, exercise responses, and stated goals $\left.{ }^{63}\right]$. Further, behaviourally based exercise interventions, the use of behaviour change strategies, supervision by an experienced fitness instructor, and exercise that is pleasant and enjoyable can improve adoption and adherence to prescribed exercise programs.

Body temperature measurements are instrumental for personalised couching towards regular physical activities in school children as demonstrated in this article.

\section{Declarations}

Authors' contributions: Study concept ADB; PPPM, analysis concepts OG; experimental work ADB, MS, AS, HP; validation AS, HP, OG; analysis ADB, MS, AS, HP; investigation, data curation ADB, MS, HP; OG, original draft preparation $A D B$; review and editing HP; OG, visualization ADB, HP, MS; supervision AS, HP.

\section{Funding information}

This research was funded by statutory funds of the University School of Physical Education in Wroclaw and the Wroclaw University of Science and Technology.

\section{Ethical approval and consent to participate}


The study was conducted under the permission of the Senate Committee of Ethics of Scientific Research at the University School of Physical Education (Permission 28.06.2007).

\section{Consent for publication}

The authors declare that they agree with the publication.

\section{Competing interests}

The authors declare that they have no competing interests.

\section{Availability of data and material}

All study relevant data are presented in the manuscript.

\section{Code availability}

Not applicable

\section{References}

1. Piercy KL, Troiano RP, Ballard RM, Carlson SA, Fulton JE, Galuska DA, George SM, Olson RD. The Physical Activity Guidelines for Americans. JAMA. 2018 Nov 20;320(19):2020-2028. doi: 10.1001/jama.2018.14854.

2. Giroir BP, Wright D. Physical Activity Guidelines for Health and Prosperity in the United States. JAMA. 2018;320(19):1971-1972. doi: 10.1001/jama.2018.16998.

3. Warburton DER, Bredin SSD. Health benefits of physical activity: a systematic review of current systematic reviews. Curr Opin Cardiol. 2017;32(5):541-556. doi: 10.1097/HC0.0000000000000437.

4. Chaput JP, Willumsen J, Bull F, Chou R, Ekelund U, Firth J, Jago R, Ortega FB, Katzmarzyk PT. 2020 WHO guidelines on physical activity and sedentary behaviour for children and adolescents aged 517 years: summary of the evidence. Int J Behav Nutr Phys Act. 2020;17(1):141. doi: 10.1186/s12966020-01037-z.

5. Ortega FB, Ruiz JR, Castillo MJ, Sjöström M. Physical fitness in childhood and adolescence: a powerful marker of health. Int J Obes (Lond). 2008;32(1):1-11. doi: 10.1038/sj.ijo.0803774.

6. Ruiz JR, Castro-Piñero J, Artero EG, Ortega FB, Sjöström M, Suni J, Castillo MJ. Predictive validity of health-related fitness in youth: a systematic review. Br J Sports Med. 2009;43(12):909-23. doi: 10.1136/bjsm.2008.056499.

7. Pascoe M, Bailey AP, Craike M, Carter T, Patten R, Stepto N, Parker A. Physical activity and exercise in youth mental health promotion: a scoping review. BMJ Open Sport Exerc Med. 2020;6(1):e000677. doi: 10.1136/bmjsem-2019-000677.

8. Pate RR, Flynn JI, Dowda M. Policies for promotion of physical activity and prevention of obesity in adolescence. J Exerc Sci Fit. 2016;14(2):47-53. doi: 10.1016/j.jesf.2016.07.003. 
9. Graf C. Preventing and treating obesity in pediatrics through physical activity. EPMA J. 2011;2(3):261-70. doi: 10.1007/s13167-011-0091-0.

10. Brown T, Moore TH, Hooper L, Gao Y, Zayegh A, ljaz S, Elwenspoek M, Foxen SC, Magee L, O'Malley C, Waters $\mathrm{E}$, Summerbell CD. Interventions for preventing obesity in children. Cochrane Database Syst Rev. 2019;7(7):CD001871. doi: 10.1002/14651858.CD001871.pub4.

11. Wendt $D$, van Loon LJ, Lichtenbelt WD. Thermoregulation during exercise in the heat: strategies for maintaining health and performance. Sports Med. 2007;37(8):669-82. doi: 10.2165/00007256200737080-00002.

12. Osilla EV, Marsidi JL, Sharma S. Physiology, Temperature Regulation. 2021. In: StatPearls [Internet]. Treasure Island (FL): StatPearls Publishing; 2021. PMID: 29939615.

13. Lim CL, Byrne C, Lee JK. Human thermoregulation and measurement of body temperature in exercise and clinical settings. Ann Acad Med Singap. 2008;37(4):347-53.

14. Knobel RB, Guenther BD, Rice HE. Thermoregulation and thermography in neonatal physiology and disease. Biol Res Nurs. 2011;13(3):274-82. doi: 10.1177/1099800411403467.

15. Kasprzyk T, Cholewka A, Kucewicz M, Sieron K, Sillero-Quintana M, Morawiec T, Stanek A. A quantitative thermalanalysis of cyclists' thermo-active base layers. J Therm AnalCalorim. 2019;136:1689-99 https://doi.org/10.1007/s10973-018-7775-9.

16. McLellan TM. The importance of aerobic fitness in determining tolerance to uncompensable heat stress. Comp Biochem Physiol A Mol Integr Physiol. 2001 Apr;128(4):691-700. doi: 10.1016/s10956433(01)00275-6.

17. Drust $B$, Rasmussen $P$, Mohr M, Nielsen B, Nybo L. Elevations in core and muscle temperature impairs repeated sprint performance. Acta Physiol Scand. 2005;183(2):181-90. doi: 10.1111/j.1365201X.2004.01390.x.

18. Chudecka M, Lubkowska A, Leźnicka K, Krupecki K. The Use of Thermal Imaging in the Evaluation of the Symmetry of Muscle Activity in Various Types of Exercises (Symmetrical and Asymmetrical). J Hum Kinet. 2015;49:141-7. doi: 10.1515/hukin-2015-0116.

19. Gomes LH, Carneiro-Júnior MA, Marins JC. Thermoregulatory responses of children exercising in a hot environment. Rev Paul Pediatr. 2013 Jan-Mar;31(1):104-10. English, Portuguese. doi: 10.1590/s0103-05822013000100017.

20. Székely M, Garai J. Thermoregulation and age. Handb Clin Neurol. 2018;156:377-395. doi: 10.1016/B978-0-444-63912-7.00023-0.

21. Falk B, Dotan R. Temperature regulation and elite young athletes. Med Sport Sci. 2011;56:126-149. doi: 10.1159/000320645. Epub 2010 Dec 21. PMID: 21178371.

22. Hunold S, Mietzsch E, Werner J. Thermographic studies on patterns of skin temperature after exercise. Eur J Appl Physiol Occup Physiol. 1992;65(6):550-4. doi: 10.1007/BF00602364.

23. Etehadtavakol M, Ng EYK, Chandran V, Rabbani H. Separable and non-separable discrete wavelet transform based texture features and image classification of breast thermograms. Infrared Phys Technol. 2013;61:274-86 doi:10.1016/j.infrared.2013.08.009. 
24. Ramirez Valladolid S, Chiwo F, Osorino Martinez C, Cabrera Alonso R, Moncada B, Gonzalez Contreras F. 488 Thermal pattern determination in patients with rosacea using infrared thermography. J Invest. Dermatol. 2018;138(5):S83. doi:10.1016/j.jid.2018.03.495.

25. Bauer J, Hoq MN, Mulcahy J, Tofail SAM, Gulshan F, Silien C, Podbielska H, Akbar MM. Implementation of artificial intelligence and non-contact infrared thermography for prediction and personalized automatic identification of different stages of cellulite. EPMA J. 2020;11(1):17-29. doi: 10.1007/s13167-020-00199-x.

26. Lin YH, Chen YC, Cheng KS, Yu PJ, Wang JL, Ko NY. Higher Periwound Temperature Associated with Wound Healing of Pressure Ulcers Detected by Infrared Thermography. J Clin Med. 2021;10(13):2883. doi: 10.3390/jcm10132883.

27. Lubkowska A, Dudzińska W, Bryczkowska I, Dołęgowska B. Body Composition, Lipid Profile, Adipokine Concentration, and Antioxidant Capacity Changes during Interventions to Treat Overweight with Exercise Programme and Whole-Body Cryostimulation. Oxid Med Cell Longev. 2015;2015:803197. doi: 10.1155/2015/803197.

28. Boerner E, Bauer J, Ratajczak B, Dereń E, Podbielska H. Application of thermovision for analysis of superficial temperature distribution changes after physiotherapy comparison of infrared irradiation and cryotherapy. J Therm Anal Calorim. 2015;120(1):261-7. https://doi.org/10.1007/s10973-0144026-6.

29. Hildebrandt C, Raschner C, Ammer K. An overview of recent application of medical infrared thermography in sports medicine in Austria. Sensors (Basel). 2010;10(5):4700-15. doi: 10.3390/s100504700.

30. Costello J, Stewart I, Selfe J, Kärki A, Donnelly A. Use of thermal imaging in sports medicine research: A short report. International Sportmed J. 2013;14. 94-98. http://www.ismj.com/Pages/311417173/ISMJ/journals/Vol-14-No2-2013.asp. doi: 10.10520/EJC138120.

31. Teyhen DS, Shaffer SW, Lorenson CL, Halfpap JP, Donofry DF, Walker MJ, Dugan JL, Childs JD. The Functional Movement Screen: a reliability study. J Orthop Sports Phys Ther. 2012;42(6):530-40. doi: 10.2519/jospt.2012.3838.

32. Bonazza NA, Smuin D, Onks CA, Silvis ML, Dhawan A. Reliability, Validity, and Injury Predictive Value of the Functional Movement Screen: A Systematic Review and Meta-analysis. Am J Sports Med. 2017;45(3):725-732. doi: 10.1177/0363546516641937.

33. Smith CJ. Pediatric Thermoregulation: Considerations in the Face of Global Climate Change. Nutrients. 2019;11(9):2010. doi: 10.3390/nu11092010.

34. Dębiec-Bąk A, Pawik $t$, Skrzek A, Termoregulation of football players after cryotherapy in thermography. J Therm Anal Calorim 2016;126:1633-1644. https://doi.org/10.1007/s10973-0165623-3.

35. Inoue $Y$, Kuwahara T, Araki T. Maturation- and aging-related changes in heat loss effector function. $J$ Physiol Anthropol Appl Human Sci. 2004;23(6):289-94. doi: 10.2114/jpa.23.289. 
36. Inbar O, Morris N, Epstein Y, Gass G. Comparison of thermoregulatory responses to exercise in dry heat among prepubertal boys, young adults and older males. Exp Physiol. 2004;89(6):691-700. doi: 10.1113/expphysiol.2004.027979.

37. Leites GT, Cunha GS, Obeid J, Wilk B, Meyer F, Timmons BW. Thermoregulation in boys and men exercising at the same heat production per unit body mass. Eur J Appl Physiol. 2016;116(7):1411-9. doi: 10.1007/s00421-016-3400-4.

38. Shibasaki M, Inoue $\mathrm{Y}$, Kondo N, Iwata A. Thermoregulatory responses of prepubertal boys and young men during moderate exercise. Eur J Appl Physiol Occup Physiol. 1997;75(3):212-8. doi: $10.1007 / \mathrm{s} 004210050150$.

39. Yeargin SW, Casa DJ, Judelson DA, McDermott BP, Ganio MS, Lee EC, Lopez RM, Stearns RL, Anderson JM, Armstrong LE, Kraemer WJ, Maresh CM. Thermoregulatory responses and hydration practices in heat-acclimatized adolescents during preseason high school football. J Athl Train. 2010;45(2):136-46. doi: 10.4085/1062-6050-45.2.136.

40. Foster J, Hodder SG, Lloyd AB, Havenith G. Individual Responses to Heat Stress: Implications for Hyperthermia and Physical Work Capacity. Front Physiol. 2020;11:541483. doi: 10.3389/fphys.2020.541483.

41. Cholewka A, Kasprzyk T, Stanek A, et al. May thermal imaging be useful in cyclist endurance tests? J Therm Anal Calorim 2016;123:1973-1979. doi: 10.1007/s10973-015-4662-5.

42. Duffield R, Bird SP, Ballard RJ. Field-based pre-cooling for on-court tennis conditioning training in the heat. J Sports Sci Med. 2011;10(2):376-84.

43. Chudecka M, Lubkowska A. The use of thermal imaging to evaluate body temperature changes of athletes during training and a study on the impact of physiological and morphological factors on skin temperature. Human Movement. 2012;13(1):33-39. doi:10.2478/v10038-012-0002-9.

44. Chudecka M, Lubkowska A, Temperatures changes of selected boys surfaces of handball players in the course of training estimated by thermovision, and the study of the impact of physiological and morphological factors on the skin temperature. Journal of Thermal Biology, 2010;35:379-385. doi:10.1016/j.jtherbio.2010.08.001.

45. Rowland T. Thermoregulation during exercise in the heat in children: old concepts revisited. J Appl Physiol (1985). 2008;105(2):718-24. doi: 10.1152/japplphysiol.01196.2007.

46. Kokolus KM, Hong CC, Repasky EA. Feeling too hot or cold after breast cancer: is it just a nuisance or a potentially important prognostic factor? Int J Hyperthermia. 2010;26(7):662-80. doi: 10.3109/02656736.2010.507235.

47. Frank SM, Raja SN, Bulcao CF, Goldstein DS. Relative contribution of core and cutaneous temperatures to thermal comfort and autonomic responses in humans. J Appl Physiol (1985). 1999;86(5):1588-93. doi: 10.1152/jappl.1999.86.5.1588.

48. Liskova A, Samec M, Koklesova L, Kudela E, Kubatka P, Golubnitschaja O. Mitochondriopathies as a Clue to Systemic Disorders-Analytical Tools and Mitigating Measures in Context of Predictive, 
Preventive, and Personalized (3P) Medicine. Int J Mol Sci. 2021;22(4):2007. doi:

10.3390/ijms22042007.

49. Koklesova L, Samec M, Liskova A, Zhai K, Büsselberg D, Giordano FA, Kubatka P, Golunitschaja O. Mitochondrial impairments in aetiopathology of multifactorial diseases: common origin but individual outcomes in context of 3P medicine. EPMA J. 2021;12(1):1-14. doi: 10.1007/s13167-02100237-2.

50. Samec M, Liskova A, Koklesova L, Samuel SM, Zhai K, Buhrmann C, Varghese E, Abotaleb M, Qaradakhi T, Zulli A, Kello M, Mojzis J, Zubor P, Kwon TK, Shakibaei M, Büsselberg D, Sarria GR, Golubnitschaja O, Kubatka P. Flavonoids against the Warburg phenotype-concepts of predictive, preventive and personalised medicine to cut the Gordian knot of cancer cell metabolism. EPMA J. 2020;11(3):377-398. doi: 10.1007/s13167-020-00217-y.

51. Golubnitschaja O. Feeling cold and other underestimated symptoms in breast cancer: anecdotes or individual profiles for advanced patient stratification? EPMA J. 2017;8(1):17-22. doi: 10.1007/s13167-017-0086-6.

52. Gordon CJ. Temperature and Toxicology: An Integrative, Comparative, and Environmental Approach (1st ed.). CRC Press. 2005. https://doi.org/10.1201/9781420037906

53. Kurzrock R. The role of cytokines in cancer-related fatigue. Cancer. 2001;92(6 Suppl):1684-8. doi: 10.1002/1097-0142(20010915)92:6+<1684::aid-cncr1497>3.0.co;2-z.

54. Netea MG, Kullberg BJ, Van der Meer JW. Circulating cytokines as mediators of fever. Clin Infect Dis. 2000;31 Suppl 5:S178-84. doi: 10.1086/317513. PMID: 11113021.

55. Dehkharghani S, Fleischer CC, Qiu D, Yepes M, Tong F. Cerebral Temperature Dysregulation: MR Thermographic Monitoring in a Nonhuman Primate Study of Acute Ischemic Stroke. AJNR Am J Neuroradiol. 201738(4):712-720. doi: 10.3174/ajnr.A5059.

56. Torres Crigna A, Link B, Samec M, Giordano FA, Kubatka P, Golubnitschaja O. Endothelin-1 axes in the framework of predictive, preventive and personalised (3P) medicine. EPMA J. 2021;12(3):1-41. doi: 10.1007/s13167-021-00248-z.

57. Polivka J Jr, Polivka J, Pesta M, Rohan V, Celedova L, Mahajani S, Topolcan O, Golubnitschaja O. Risks associated with the stroke predisposition at young age: facts and hypotheses in light of individualized predictive and preventive approach. EPMA J. 2019;10(1):81-99. doi: 10.1007/s13167019-00162-5.

58. Kucera R, Pecen L, Topolcan O, Dahal AR, Costigliola V, Giordano FA, Golubnitschaja O. Prostate cancer management: long-term beliefs, epidemic developments in the early twenty-first century and 3PM dimensional solutions. EPMA J. 2020;11(3):399-418. doi: 10.1007/s13167-020-00214-1.

59. Golubnitschaja O, Liskova A, Koklesova L, Samec M, Biringer K, Büsselberg D, Podbielska H, Kunin AA, Evsevyeva ME, Shapira N, Paul F, Erb C, Dietrich DE, Felbel D, Karabatsiakis A, Bubnov R, Polivka J, Polivka J Jr, Birkenbihl C, Fröhlich H, Hofmann-Apitius M, Kubatka P. Caution, "normal" BMI: health risks associated with potentially masked individual underweight - EPMA Position Paper 2021. EPMA J. 2021;12(3):1-22. doi: 10.1007/s13167-021-00251-4. 
60. Wang W, Yan Y, Guo Z, Hou H, Garcia M, Tan X, Anto EO, Mahara G, Zheng Y, Li B, Kang T, Zhong Z, Wang Y, Guo X, Golubnitschaja O; Suboptimal Health Study Consortium and European Association for Predictive, Preventive and Personalised Medicine. All around suboptimal health - a joint position paper of the Suboptimal Health Study Consortium and European Association for Predictive, Preventive and Personalised Medicine. EPMA J. 2021. doi: 10.1007/s13167-021-00253-2.

61. Melby PS, Elsborg P, Nielsen G, Lima RA, Bentsen P, Andersen LB. Exploring the importance of diversified physical activities in early childhood for later motor competence and physical activity level: a seven-year longitudinal study. BMC Public Health. 2021;21(1):1492. doi: 10.1186/s12889021-11343-1.

62. Tandon PS, Kroshus E, Olsen K, Garrett K, Qu P, McCleery J. Socioeconomic Inequities in Youth Participation in Physical Activity and Sports. Int J Environ Res Public Health. 2021;18(13):6946. doi: 10.3390/ijerph18136946.

63. Garber CE, Blissmer B, Deschenes MR, Franklin BA, Lamonte MJ, Lee IM, Nieman DC, Swain DP; American College of Sports Medicine. American College of Sports Medicine position stand. Quantity and quality of exercise for developing and maintaining cardiorespiratory, musculoskeletal, and neuromotor fitness in apparently healthy adults: guidance for prescribing exercise. Med Sci Sports Exerc. 2011;43(7):1334-59. doi: 10.1249/MSS.0b013e318213fefb.

\section{Figures}



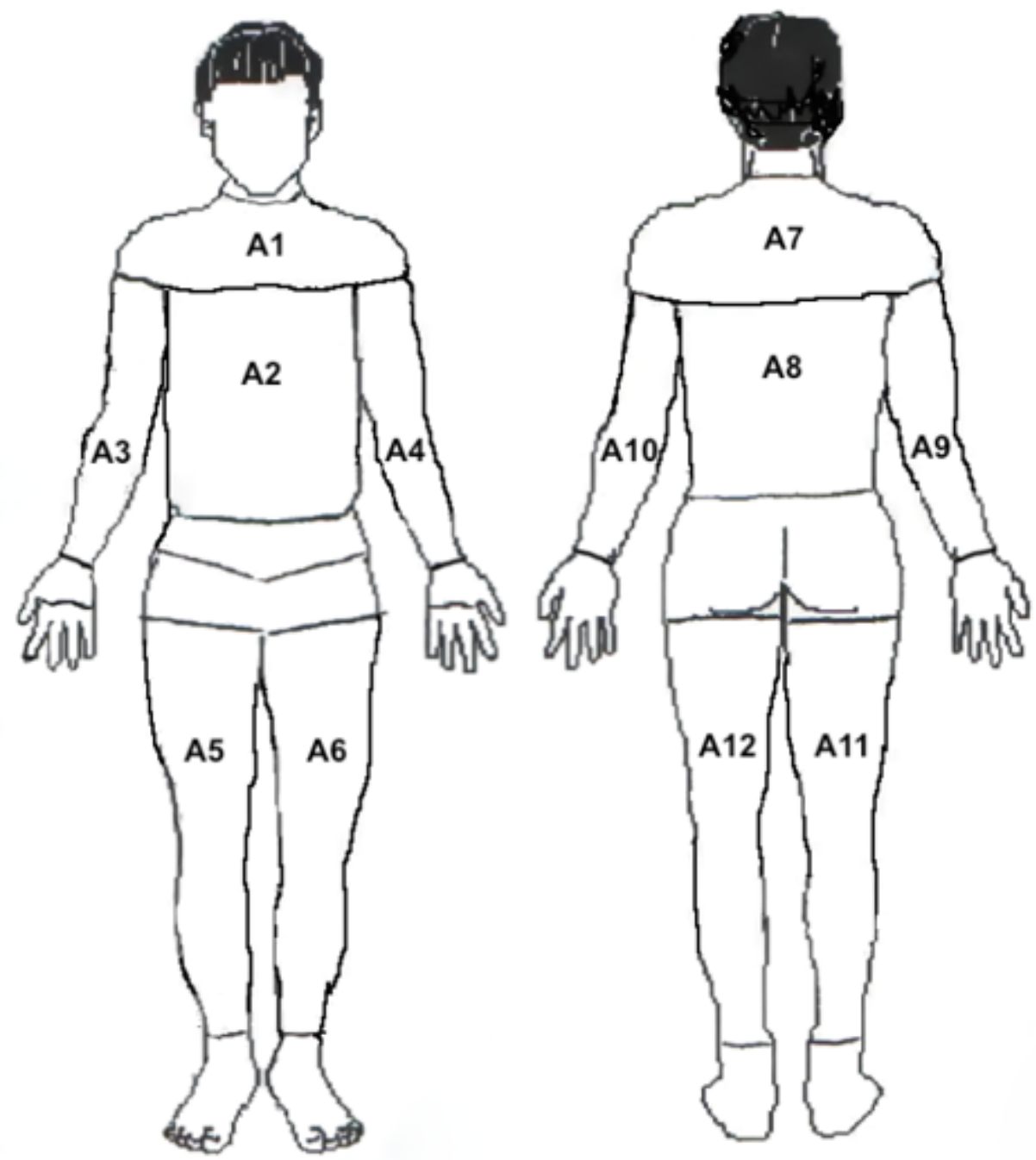

\section{Figure 1}

Schema presenting the parts of the body in which the average superficial temperature recorded by the thermographic camera, was analyzed.
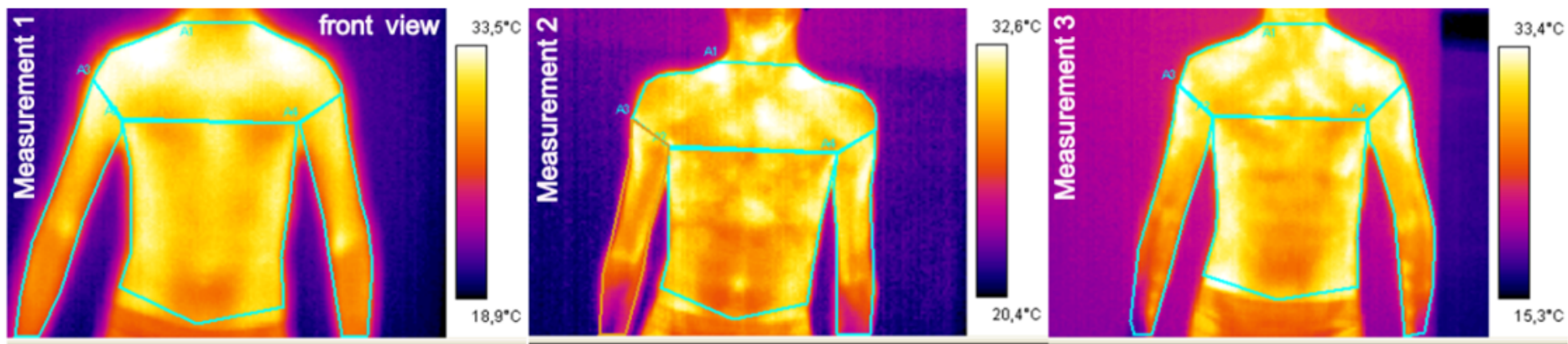

\begin{tabular}{|c|c|c|c|c|c|c|c|c|c|c|c|c|c|c|c|c|c|}
\hline \multicolumn{3}{|c|}{ 品 Analysis | to Position } & \multirow{2}{*}{$\begin{array}{l}{ }^{2 \tau} \text { \% Obj. Par } \\
\text { Max - ... }\end{array}$} & \multicolumn{2}{|c|}{ (i) Image $\mid$ 娄 Text } & \multicolumn{3}{|c|}{ 品 Analysis | \& Position| } & \multirow{2}{*}{$\begin{array}{l}{ }^{{ }^{\tau} \tau} \text { Obj. Par } \\
\text { Max - ... }\end{array}$} & (i) Image & \multicolumn{2}{|c|}{ F Text 뭉 Analysis } & \multicolumn{2}{|c|}{ | } & \multirow{2}{*}{$\begin{array}{l}\varepsilon_{\tau} \text { Obj. Par } \\
\text { Max }-\ldots\end{array}$} & (i) Image & e| 国 Te \\
\hline Label & Mn & Max & & Avg & Stdev & Label & Min & Max & & Avg & Stdev & Label & Min & Max & & Avg & Stdev \\
\hline Image & 17,7 & 33,9 & 16,2 & & & Image & 20,3 & 33,8 & 13,6 & & & Image & 14,6 & 33,9 & 19,3 & & \\
\hline A1 & 29,1 & 33,9 & 4,8 & 32,3 & 0,8 & A1 & 26,4 & 33,8 & 7,4 & 30,7 & 0,8 & A1 & 26,5 & 33,9 & 7,4 & 31,7 & 0,9 \\
\hline A2 & 28,3 & 32,8 & 4,5 & 31,2 & 0,7 & A2 & 26,5 & 32,1 & 5,6 & 29,7 & 0,9 & A2 & 25,9 & 33,5 & 7,6 & 30,5 & 1,3 \\
\hline$A 3$ & 25,8 & 33,4 & 7,6 & 30,0 & 1,6 & A3 & 21,4 & 32,0 & 10,6 & 28,0 & 2,5 & A3 & 19,5 & 33,6 & 14,2 & 28,3 & 3,0 \\
\hline A4 & 26,1 & 32,6 & 6,5 & 30,3 & 1,3 & A4 & 22,9 & 32,2 & 9,3 & 29,0 & 2,2 & A4 & 21,7 & 33,6 & 11,9 & 29,4 & 2,3 \\
\hline
\end{tabular}

Figure 2 
Exemplary thermal images of the trunk and upper limbs, front view.
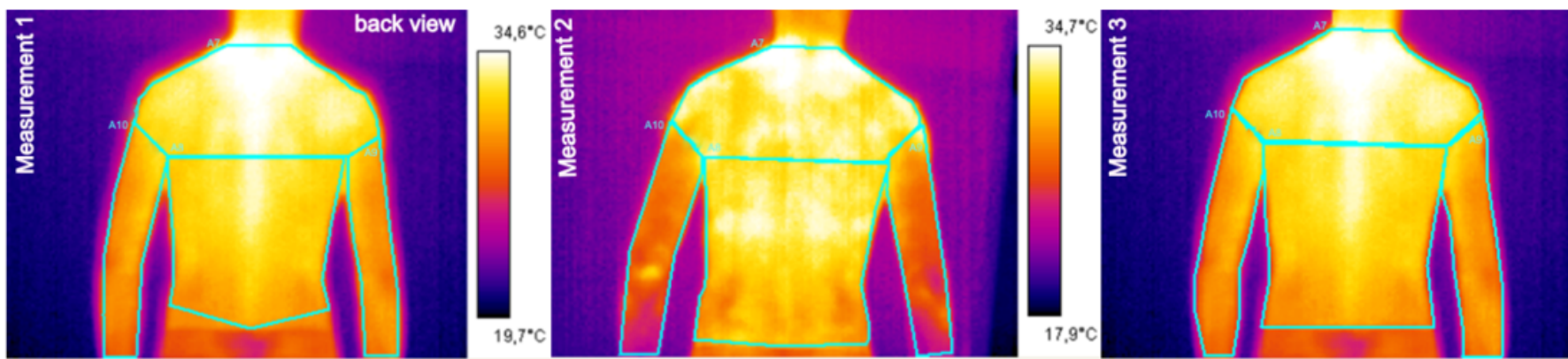

$34,6^{\circ} \mathrm{C}$

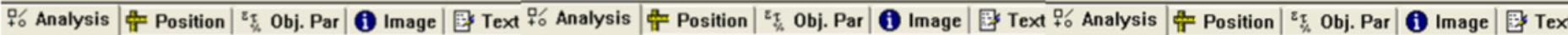

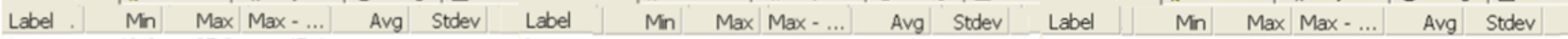
Image $\quad 19,6 \quad 35,0$

$19,6-35,0 \quad 15,4$

A7 $\quad 28,1 \quad 35,0 \quad 6,9 \quad 33,4 \quad 0,7$

$16,1 \quad 35,2 \quad 19,1$

19,1 Avg Stdev $-\frac{\text { Label }}{\text { Image }}$

19,6

$35,0 \quad 15,4$

A8 $28,4 \quad 34$,

$\begin{array}{lll}5,7 & 32,2 & 0,8\end{array}$

$30,2 \quad 35,2$

$4,9 \quad 33,3$

$0,6 \quad$ A7

$24,6 \quad 34,3$

A10

$\begin{array}{ll}27,4 & 32,8 \\ 24,6 & 33,0\end{array}$

$5,4 \quad 30,9$

$\begin{array}{llll}8,5 & 30,6 & 1,3 & \text { A10 }\end{array}$

$22,3 \quad 34,0$

$9,7 \quad 32,2$

1,2 A8

$22,0 \quad 33,2$

$\begin{array}{llll}11,1 & 28,0 & 2,3 & \text { A9 }\end{array}$

$27,0 \quad 35,0$

$8,0 \quad 33,4$

$33,4 \quad 1,0$

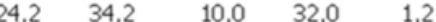

$22,9 \quad 32,9$

$10,0 \quad 30,6$

$\begin{array}{lll}9,7 & 30,3 & 1,7\end{array}$

\section{Figure 3}

Exemplary thermal images of the trunk and upper limbs, back view.
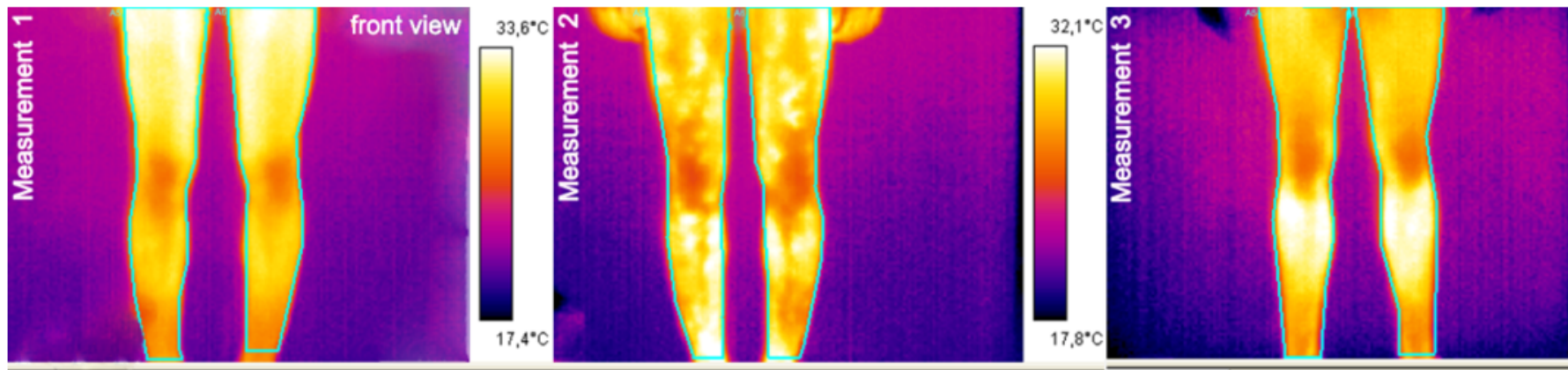

$33,0^{\circ} \mathrm{C}$

\begin{tabular}{|c|c|c|c|c|c|c|c|c|c|c|c|c|c|c|c|c|c|}
\hline +o Analysis & \multicolumn{2}{|c|}{ 寊 Position } & \multirow{2}{*}{$\begin{array}{l}\varepsilon_{\tau}^{\tau} \text { Obj. Par } \\
\text { Max }-\ldots\end{array}$} & (i) Image & \multicolumn{2}{|c|}{ | 国 Text $+\circ$ Analysis } & \multicolumn{2}{|c|}{ | Pesition Posit } & $\varepsilon_{\tau}$ Obj. Par & \multicolumn{2}{|c|}{ (i) Image } & 品 Analysis & \multicolumn{3}{|c|}{$\mid \frac{\mathrm{S}}{\mathrm{T}}$ Position ${ }^{\varepsilon_{\tau}}$ Obj. Par } & \multirow{2}{*}{$\begin{array}{c}\text { (i) Image } \\
\text { Avg }\end{array}$} & \multirow{2}{*}{$\begin{array}{l}\text { 娄 Text } \\
\text { Stdev }\end{array}$} \\
\hline Label & Min & Max & & Avg & Stdev & Label & $\mathrm{Min}$ & Max & Max - ... & Avg & Stdev & Label & Min & Max & Max - ... & & \\
\hline Image & 17,2 & 34,0 & 16,7 & & & Image & 16,8 & 32,9 & 16,1 & & & Image & 18,3 & 33,5 & 15,2 & & \\
\hline A5 & 22,3 & 33,7 & 11,4 & 30,7 & 2,0 & A5 & 22,0 & 32,9 & 10,9 & 29,4 & 1,6 & A5 & 20,9 & 33,5 & 12,6 & 29,8 & 2,0 \\
\hline A6 & 23,8 & 34,0 & 10,1 & 30,8 & 1,8 & A6 & 22,0 & 32,3 & 10,3 & 29,1 & 1,6 & A6 & 21,3 & 33,4 & 12,1 & 29,9 & 1,9 \\
\hline
\end{tabular}

\section{Figure 4}

Exemplary thermal images of the lower limbs, front view.
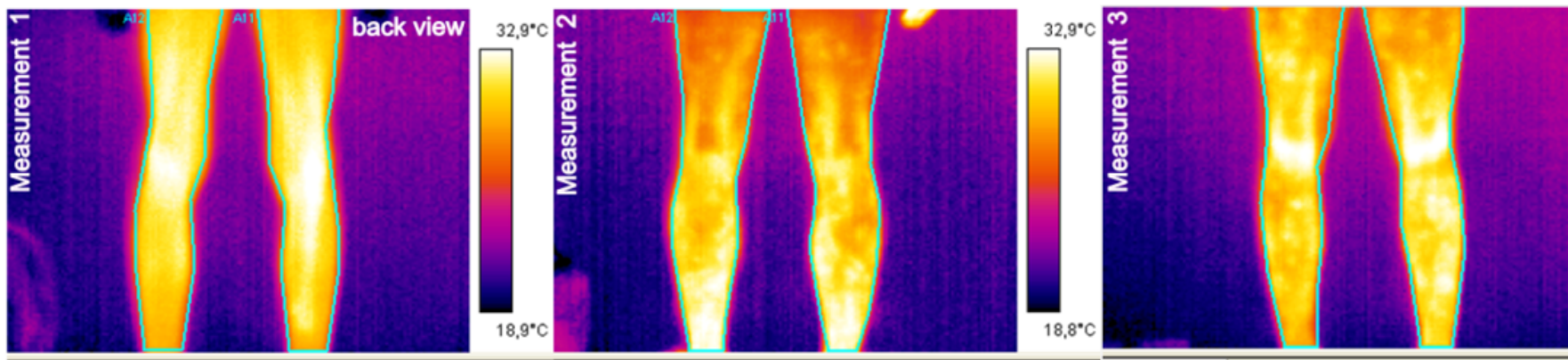

$32,2^{\circ} \mathrm{C}$

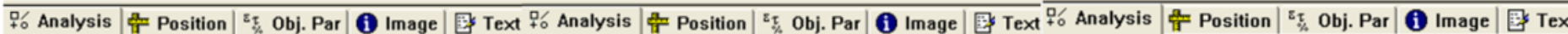

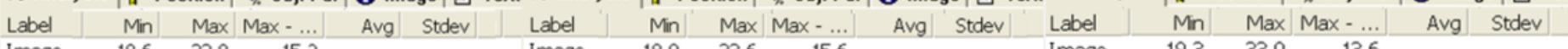

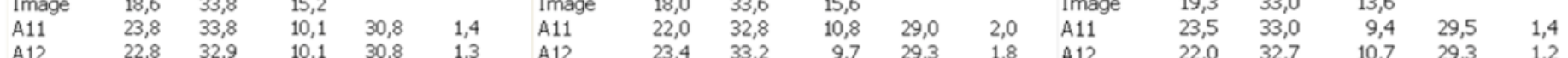


Figure 5

Exemplary thermal images of the trunk and upper limbs, back view.

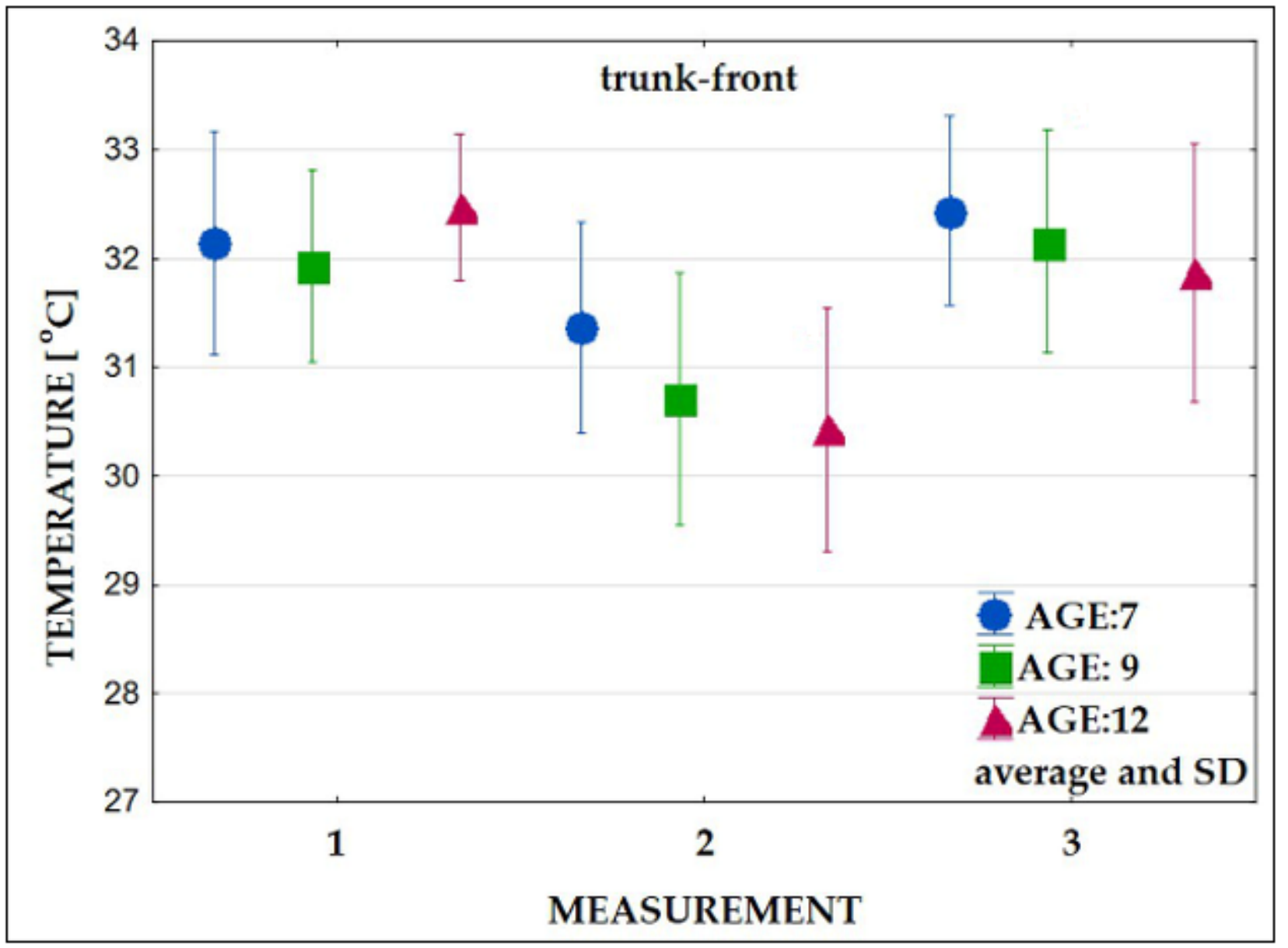

Figure 6

Changes in the superficial temperature of the trunk's front part in three age groups (Measurements: 1, 2 and 3). 


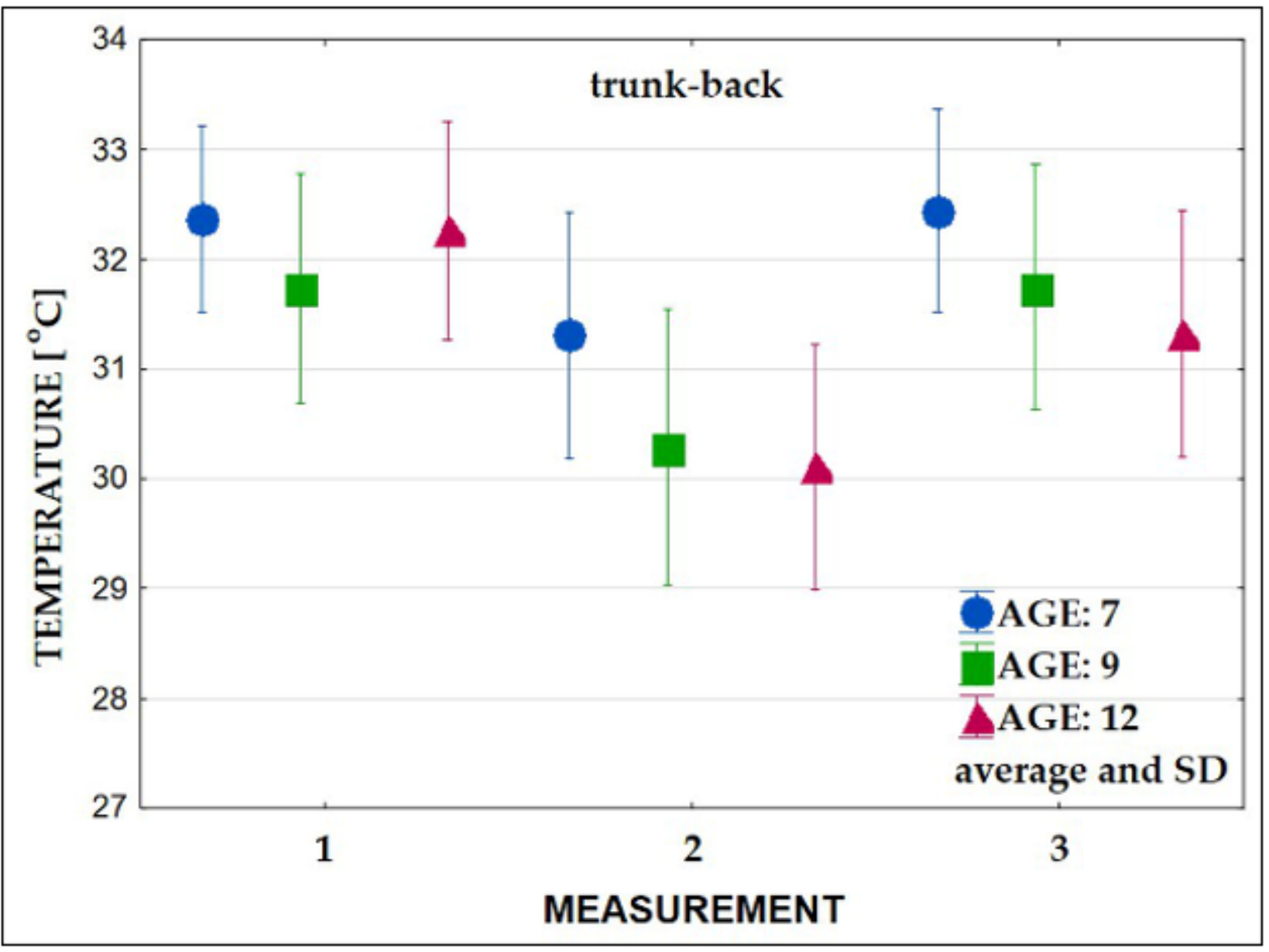

Figure 7

Changes in the surface temperature of the trunk's back part in three age groups (Measurements: 1, 2 and 3). 


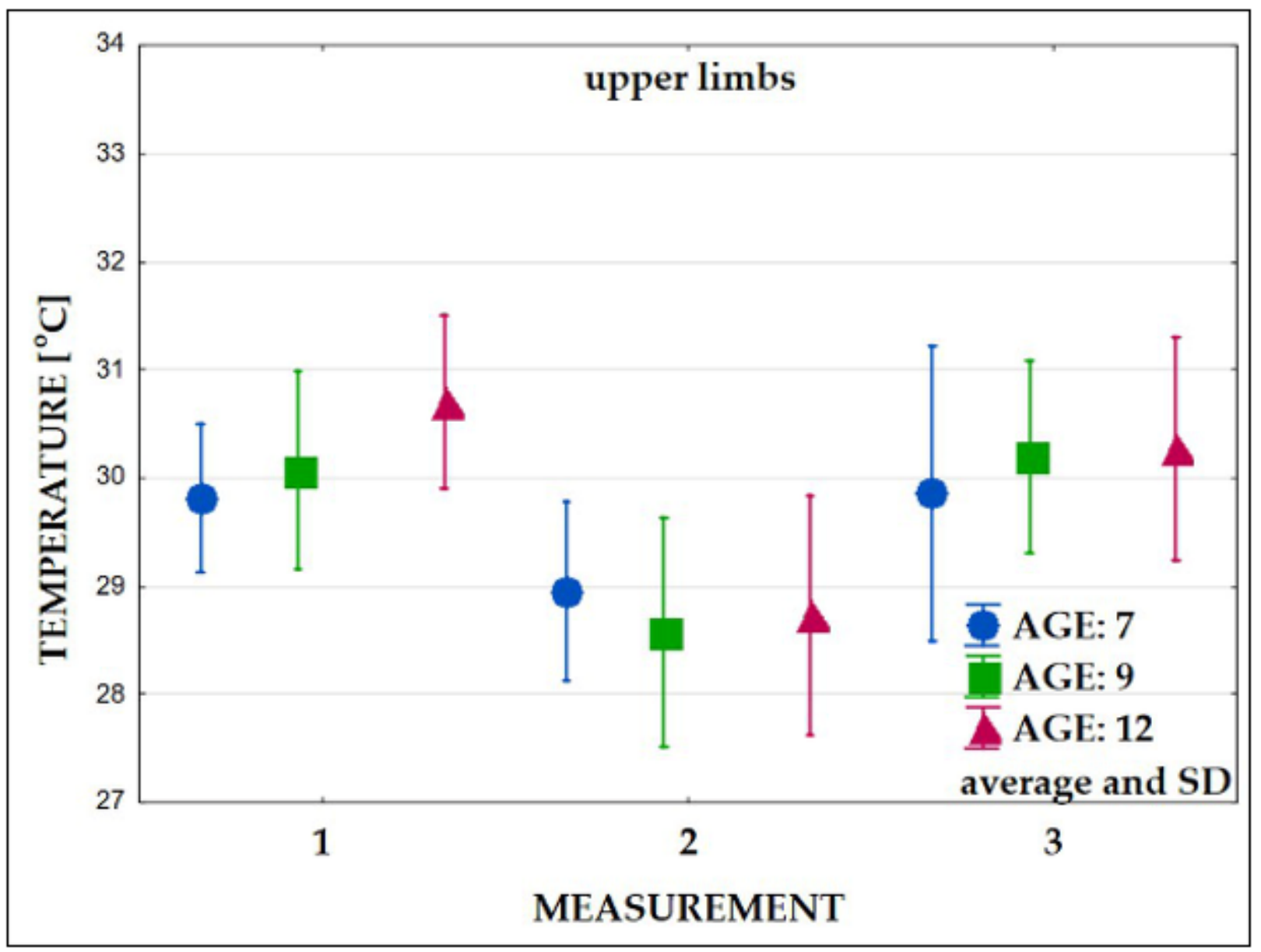

Figure 8

Changes in the superficial temperature of the upper limbs in three age groups (Measurements: 1, 2 and $3)$. 


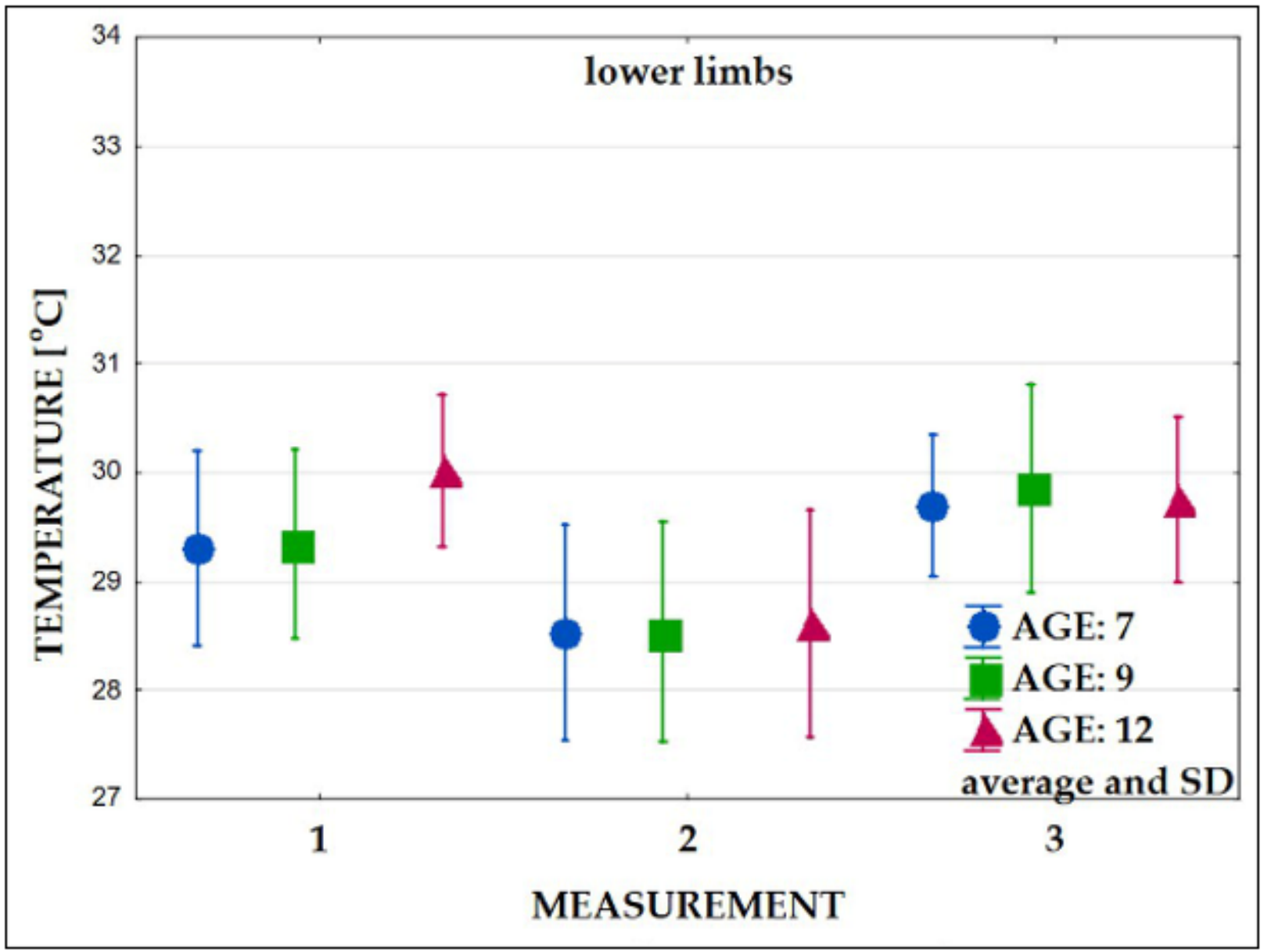

Figure 9

Changes in the surface temperature of the upper limbs in three age groups (Measurements: 1, 2 and 3). 